\title{
EDITORIAL
}

\section{ETHICAL ISSUES IN MEDICAL RESEARCH \& PUBLICATIONS}

Ethical issues is medical researches and publication is utmost important, which were some how ignored or less emphasized in the previous days. Presently it is being practiced in all the institutions where post graduate courses are running. Institutional Review Board (IRB) are meticulously exercising the matter. Bulk number of post gradate students are now in the pipeline waiting to enter in to the clinical courses in FCPS and Masters in different disciplines. They are being exposed in dissertation or thesis preparation. Many organizational bodies are carrying out the orientation courses to expose post graduate students that how to write scientific papers. Obviously this includes a portion to teach them the ethical issues in medical researches. This part of the exposure was not getting proper attention in the earlier days. So, many of the researcher could not be able to publish their scientific papers in the international indexed medical journal due to lack of proper maintenance of ethics in medical research.

We should be very concern about the ethics. So that we can gain proper attention and less debate. Research in medicine is an activity conducted with the intent to produce new knowledge. Research may be basic or clinical, retrospective or prospective. Research foster new knowledge and improves clinical practice by improving diagnostic and therapeutic strategies. It is the medical activity that aims at the future.

The term ethics derived from the Greek word "Ethos" which means custom or habit. Moral is another term very close to ethics. "Moral" is derived from the Latin word "Mores" which also means custom or habit. Thus ethics may be defined as mens habit or custom or in other word character and principles on which they act and consider rightness or wrongness, the good or evil of those habit.

Ethics in other word the norms or code of conduct. Norms are the standard by means of which we can judge certain conduct as right or good.

Bioethics is the study of the moral and social implications of techniques resulting from advances in the biological Sciences. Bioethical theory comprises three main principles Autonomy. Beneficence and Justice. Other subsidiary principles are informed consent, truth telling and confidentiality.

The importance of bioethics serves as an instrument of change in medicine, Law, and social attitudes. Bioethics strengthen the right of patients and research subjects and to improve conceptions of the appropriate use of medical technology and of the proper goals of medicine.

Research ethics is based on the premise that it is ethical to experiment on humans in carefully controlled conditions.

The ethical requirements in the research on human are obtaining informed consent from the potential subjects, deriving benefits from the experiment and keeping the risk of the subject as small as possible. It is possible to perform the research by keeping the ethical as well as scientific criteria in mind.

Publishing in an arduous process and involves searches and use of ideas, knowledge and findings from different sources, do they be print materials, audio visual materials, knowledge from friends or peers and knowledge from the nature or materials from any other sources all are aimed at transmitting knowledge from one mind to another mind for the benefit of mankind and the environment. Publication plays an important role in dissemination of new knowledge or ideas. Thereby making new contributions to the world body of knowledge.

Accuracy, Honesty and integrity of used and generated ideas or knowledge are highly important components of writing and publishing. Publication ethics mainly cover, conceptualization of a research topic, integrity in presentation of ideas, research/ study design, ethical approval of research protocol, analysis of data, misinterpretation of facts or observations, determination of authorship, conflict interest, redundant publication, plagiarism and other related matters. Breaching of publication ethics may be term as scientific misconduct. 
According to cope report 1999 guide line on good publication practice has been issued.

All research involving human subjects should be conducted in accordance with there basic principles (a) respect to persons (b) Beneficence (c) Justice

Respect to Persons: Incorporates at least two fundamental ethical considerations.

i) Respect for autonomy, which requires that those who are capable of deliberation about their personal choices should be treated with respect for their capacity for self determination.

ii) Protection of person with impaired or diminished autonomy, which require that those who are dependent or vulnerable be afforded security against harm or abuse.

Beneficence : Beneficence refers to the ethical obligation to maximize benefits and to minimize harms. The risk of research be reasonable in the light of expected benefits. Research design should be sound and the investigators be competent to conduct research and to safe guard the welfare of the research subjects. Do no harm.

Justice : Justice refers to ethical obligation to treat person in accordance with what is morally right and proper to give each person what is due to him.

As stated in Paragraph 32 of the Declaration of Helsinki "In the treatment of a patient where proven prophylactic; diagnostic and therapeutic methods do not exist or have been ineffective, the physician with informed consent from the patient must be free to use unproven of new measures if the physician's judgment it offers hope of saving life reestablishing health or alleviating suffering."

The Guide lines are

Guideline 1 : Ethical Justification and scientific Validity of biomedical research involving human beings.

\section{Guideline 2 : Ethical review committees}

All proposals to conduct research involving human subjects must he submitted for review of their scientific merit and ethical acceptability to ethical review committee. Investigator must obtain their approval or clearance before undertaking their research.

Guideline 3 : Ethical review of externally sponsored research.
The health authorities of the host country as well as national or local review committee should ensure that the proposed research is responsive to the health needs Priorities of the host country and meet the requisite ethical standard.

Guideline 4 : Individual informed consent.

For all biomedical research involving humans, the investigator must obtain the voluntary informed consent of the prospective subject or permission of a legally authorized representation.

\section{Guideline 5 : Inducement to Participate}

Subjects may be reimbursed for lost earnings, travel costs, and other expenses incurred in taking part in a study.

Guideline 6 : Benefits and risks of study participation

For all biomedical research involving human subjects, the investigator must ensure that Potential benefits and risk are reasonably balanced and risks are minimized.

Guideline 7 : Safeguarding Confidentiality.

Investigator must establish secure safe guards of the confidentiality of subjects research data. Subjects should be told the limits, legal or other, to the investigator's ability to safe guard confidentiality and the possible Consequences of breach's of confidentiality.

Guideline 8 : Right of injured subjects to treatment and compensation.

Investigators should ensure the research subjects who suffer injury as a result of this participation are entitled to free treatment and such financial and other assistance as compensation.

Research has to be based on ethics and mutual trust between the investigations and research participant. The declaration of Helsinki required that clinical trials should he performed only on volunteers. the risk benefit ratio should be low to Justify the research effort. Following Institutional Review Board (IRB) approval, research participant must be informed about the nature of the research. Consent should he obtained and alternate therapeutic modalities should he explained and offered to the patient.

Ethical guideline for public announcement of research is not appropriately needed or relevant to the researcher. 
Among many ethical issues, Proprietary interest, financial gain, Personal recognition and promotion have less importance than accountability, honesty and integrity. Validity of our research work is directly related to Honesty, integrity and accountability.

Sometimes scientist become biased and on pressure from funding authorities and involves in fraud in research.

Ethical issues related to embryonic stem cell research assumed an important platform with scientist, politicians and theologizes. The story of January 12, 2006 at Seoul, South Korea teaches us that plagiarism and fraud cannot persist. Scientist must ensure the safety and efficacy of new drugs and treatment. Pharmaceutically biased scientific publications should not be taken as a guarantee by researchers. Even post marketing surveillance study could be done if necessary.

The relationship between pharmaceutical companies and researcher should be very transparent. The international committee of medical Journal Editors (ICMJE) and the World Health Organization (WHO) have enclosed the registration of clinical trials. NEJM, JAMA, Annals of Internal Medicine now require clinical trial registration for publication in their journal.

Also it is of utmost importance that ICMJE has set criteria of authorship of papers submitted to biomedical Journals. Authorship credit should be based on

(a) Substantial contributions to the conception and design or acquisition of data or analysis and interpretation of data.

(b) Drafting the article or revising it critically for important intellectual content.

(c) Final approval of the version to be published.

Authors should meet all three conditions. Acquisition of funding, collecting data or general supervision of a research group does not justify authorship.

It is also important to know that individuals who perform clinical service to patients as a part of their routine work are not eligible for co author unless they have contributed substantially to the research project.

\section{Conclusion :}

Research is a highly complex intellectual activities especially in medicine our professionals should conduct research to unravel the mysteries or disease, replace speculation with fact and improve diagnostic and medical management of diseases. The research should always abide by a code of ethics or medical professions protect the interest of the patient and the community and avoid biasness.

Each institutions should monitor the scientific activities or the researcher through the institutional review committee. National Biological and medical ethical committee should be formed to monitor each institution. National committee's guideline should he available at all institution so that there should be uniformity in research activity throughout the country.

\section{Dr. Quazi Tarikul Islam ${ }^{1}$, Prof. AKM Rafiquddin $^{2}$ \\ ${ }^{1}$ Department of Medicine, Rajshahi Medical College, Rajshahi, ${ }^{2} \mathrm{Head}$ of the Department of Medicine, Enam Medical College, Savar, Dhaka \\ Email: drtarique@librabd.net}

\section{References :}

1. Kahalid T, Alkawi MZ. Ethics in medical research and publication. Ann saudi med 2006:26(4); 257-60

2. Khanam RA, Introduction to ethics, bioethics and research ethics. Department of Philosophy. Dhaka University, Dhaka (Lecture) 2000.

3. T. Happes, J, Zembeny ed. Social ethics, New York, McGraw Hill, 1987.

4. E Winkler, J coombs ed, Applied ethics : A Reader, oxford : Bladewell 1993.

5. Family Practice 2000; $17: 218-21$

6. Nakamra T, Akui M, Singsby BT. Japan's ethical guide lines for epidemiological research: a history for their development. J Epidemol 2005; 15(4): 017-112

7. Henry DA. Kerridge IH. Hill SR. McNeil PM. Dorann E et al. Medical Specialist and Pharmaceutical Industry sponsored research. A Survey of the Australian experience. Med j Aust 2005; 182(11): 549-50.

8. Hawang WS, Roh SI, Lee BC et al. patient specific embryonic stem cell derived from human SCNT blast cysts. Science 2005; 308: 1777-83 